\title{
Typing of Chlamydia psittaci to monitor epidemiology of psittacosis and aid disease control in the Netherlands, 2008 to 2013
}

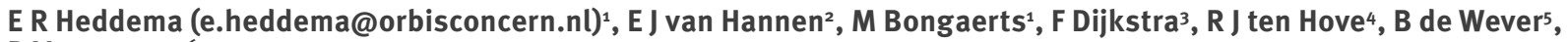
D Vanrompay ${ }^{6}$

1. Department of Medical Microbiology and Infection Control, Orbis Medical Centre, Sittard-Geleen, the Netherlands

2. Department of Medical Microbiology and Immunology, St. Antonius Hospital, Nieuwegein, the Netherlands

3. Centre for Infectious Disease Control Netherlands, National Institute for Public Health and the Environment, Bilthoven, the Netherlands

4. Department of Medical Microbiology, Rijnstate, Velp, the Netherlands

5. Department of Medical Microbiology, Academic Medical Centre, Amsterdam, the Netherlands

6. Department of Molecular Biotechnology, Faculty of Bioscience Engineering, Ghent University, Ghent, Belgium

Heddema ER, van Hannen EJ, Bongaerts M, Dijkstra F, ten Hove RJ, de Wever B, Vanrompay D. Typing of Chlamydia psittaci to monitor epidemiology of psittacosis and aid disease control in the Netherlands, 2008 to 2013. Euro Surveill. 2015;20(5):pii=21026. Available online: http://www.eurosurveillance.org/ViewArticle. and aid disease contro
aspx?Articleld $=21026$

A simple genotyping method was developed and validated for all known Chlamydia psittaci reference genotypes. $C$. psittaci is currently divided into nine genotypes (A-F, E/B, M56 and WC), all more or less associated with the preferred avian host. This method targeting variable domain 4 of the ompA gene has a lowest detection limit of 1 to 10 copies per PCR and was applied to 69 human samples collected in nine hospitals in the Netherlands from September 2008 until the end of October 2013. Genotype A was the most prevalent genotype. In addition, genotypes $B, C$, a new genotype, and $C$. abortus were found. A C. caviae infection was detected as a result of extension of this surveillance study to the national level. The sensitivity of this method compared with our real-time diagnostic PCR was 0.98 (66/67 typable samples). Specificity was 1.0 based on 33 commonly encountered bacterial and yeast species and 20 human respiratory samples. This typing method could help monitor $C$. psittaci infections in humans and provides insight into the relationships between notified human 'psittacosis' cases and the probable avian and other animal sources. When needed, a result can be obtained within 24 hours.

\section{Introduction}

Psittacosis, a notifiable disease in many countries, is caused by Chlamydia psittaci (also known as Chlamydophila psittaci). Clinical signs of psittacosis range from none to life-threatening disease requiring admission to intensive care. In 1999, Everett et al. proposed splitting the single genus Chlamydia into two genera, Chlamydia and Chlamydophila, based on clustering analyses of the $16 \mathrm{~S}$ rRNA and $23 \mathrm{~S}$ rRNA genes [1]. However, taxonomic separation of the genus based on ribosomal sequences is not consistent with the natural history of the organism as revealed by recent genome comparisons. Consequently, the proposal was made to reunite the Chlamydia in a single genus [2]. The single genus nomenclature was published in the latest edition of the Bergey's Manual of Systematic Bacteriology [3]. C. psittaci is currently divided into nine genotypes (A-F, E/B, M56 and WC), all more or less associated with the preferred avian host in each case.

The genotypes WC and $M_{5} 6$ have been found in cattle and a muskrat, respectively, and are probably not associated with birds [4]. Genotype A is associated with Psittaciformes (cockatoos, parrots, parakeets, lories), B with Columbiformes (doves and pigeons), C with Anseriformes (mainly ducks and geese) and D with turkeys. Genotype $\mathrm{E}$ is the most diverse; ca $20 \%$ of strains were isolated from pigeons, but genotype $E$ has also been found in ratites. Genotype E/B is mainly associated with ducks. Genotype $F$ is encountered rarely in Psittaciformes and Turkeys [5]. C. psittaci, together with the closely related $C$. abortus, has also been found in cattle [6]. The role of these mammals as vectors of zoonotic Chlamydia spp. infections still needs to be established.

For epidemiologic purposes, characterisation of C. psittaci in human samples provides knowledge on the most prevalent genotypes in human infections, infers probable avian sources and aids in the process of notification, surveillance and outbreak management. For decades, the diagnosis has been based on serological tests. In the past decade, diagnostic C. psittaci PCR assays were developed and introduced in the clinical setting. In the Netherlands this aided the diagnostic process for suspected psittacosis cases $[7,8]$. One of the advantages of the PCR approach over serological testing is the presence of $C$. psittaci DNA in these clinical samples. These samples are therefore suitable for further genotyping assays. Genotyping 
can be done by real-time PCR with competitor probes [9], melting curve analysis [10], MLVA [11], MLST [4], microarray or other sequence analysis [12]. Previously, a sequencing-based approach aimed at the outer membrane protein gene (ompA) was successful on human clinical samples, but the method proved laborious and was not very sensitive, mainly owing to the relatively long PCR product and abundant side products [13].

Culturing of C. psittaci could provide sufficient DNA for more in-depth typing methods such as MLVA or MLST. However, culturing is hampered by limited sensitivity, previous antibiotic use and the necessarily strict biosafety regulations. When culturing C. psittaci, biosafety level 3 precautions are needed. Nowadays, C. psittaci is only cultured in a few specialised laboratories.

None of the above typing methods has been evaluated on more than a handful of human samples. Even in a recently described outbreak of psittacosis in Sweden, only four of 12 available human samples could be typed [14]. In this study, we describe a new simple typing method for $C$. psittaci based on variable domain 4 (VD4) of the ompA gene. It does not require any specialised equipment other than a real-time PCR cycler and a (remote) sequencing facility. This method was applied directly on human samples positive for $C$. psittaci.

\section{Methods}

\section{Bacterial strains and control DNA}

C. psittaci genotypes A-F, E/B, M56 and WC were used as positive controls. The following strains were used: Genotype A: Orni (human), Genotype B: $\mathrm{CP}_{3}$ (pigeon), Genotype C: GR9 (German duck), Genotype D: NJ1 (New Jersey turkey), Genotype E: CPMN (human), Genotype F: VS225 (parakeet), Genotype E/B: WS/RT/E30 (German duck), Genotype M56 (muskrat), Genotype WC (Bos taurus). A quantified $(15,000$ copies per $\mu \mathrm{l})$ commercially available C. psittaci DNA (Amplirun C. psittaci genotype A control, Vircell, Granada, Spain) control was used for determination of the lower limit of detection. The new assay was evaluated with the Quality Control for Molecular Diagnostics (QCMD, Glasgow, Scotland) External Quality Assessment (EQA) pilot panel for C. psittaci 2013 (CPS13).

The following strains and samples were used for specificity testing: 27 ATCC (American type culture collection) strains, one NCTC (National Collection of Type Cultures, Public Health England) strain and three Dutch quality control (SKML; Dutch Foundation for Quality Assessment in Medical Laboratories) strains, as well as QCMD EQA Mycoplasma pneumoniae/Chlamydia pneumoniae panel CP.MP13 samples 09 and 05 containing C. pneumoniae and M. pneumoniae DNA (Table 1).
Clinical samples and DNA extraction

For specificity testing, 20 respiratory samples negative for C. psittaci DNA were tested with the newly developed typing method.

Clinical samples (sputa, bronchoalveolar lavage fluid, (naso)pharyngeal swabs and serum) positive in diagnostic C. psittaci PCRs were obtained from nine hospital laboratories from the Netherlands. Most of these laboratories use real-time PCRs that detect, but do not differentiate, at least C. psittaci and C. abortus and sometimes also $C$. caviae and $C$. felis $[7,8]$. This means that clinical samples could contain these very closely related species as well. Nucleic acid purification was performed at the nine Dutch laboratories with the Magnapure (Roche Diagnostics), EasyMag (BioMérieux) or Versant kPCR Molecular system (Siemens Healthcare Diagnostics). Two clinical samples were obtained from Scotland and related to a previously reported outbreak [15]. Clinical samples and/or eluates were sent to the Orbis Medical Centre in the Netherlands for further analysis. Archived samples were collected from 2008 to 2012. Since September 2012, the typing method has been implemented nationally and samples have prospectively been typed and reported to submitting laboratories and public health authorities.

For validation experiments, nucleic acids were purified with the Versant KPCR Molecular system using Sample Preparation (SP) Kit 1.0 with SP protocol $250 \mu \mathrm{l} \mathrm{sam-}$ ple input and $100 \mu$ l eluate output (Siemens Healthcare Diagnostics). All positive control strains were spiked with a background of pooled C. psittaci-negative sputum samples to simulate the diagnostic setting as close as possible. QCMD samples were processed according to the accompanying instructions.

This research was submitted for consideration to our local accredited medical ethical research committee METC Atrium-Orbis-Zuyd. According to this committee, this research does not fall under the scope of the Medical Research Involving Human Subjects Act. All prospective samples were obtained for diagnostic use and handled accordingly. Retrospective samples were analysed anonymously to the extent reasonably possible.

\section{PCR based on variable domain 4 of the ompA gene}

With the aid of PrimerzPlus, a new primer set was developed to include a variable part of the $о m p A$, the VD4 domain [16]. The amplified VD4 sequence permits differentiation of at least nine C. psittaci genotypes (A-F and $\mathrm{E} / \mathrm{B})$ and the closely related C. abortus. The primer set was verified with in-silico amplification [17] and revealed positive results for available C. psittaci genomes and C. abortus S26/3 only (setting: 'maximum two mismatches allowed'). The primer set consisted of CPVDF 5'-GTC AAG AGC AAC TTT TGA TGC-3' and CPVDR 5'-ATT TTG TTG ATC TGA ATC GAA GC-3' (nucleotide positions CPVDF 897-917 and CPVDR 
1,057-1,079 of the ompA gene of the C. psittaci VS1 strain, GenBank accession number AY762608). A fragment between 174 and 183 base pairs, depending on the genotype, is amplified. C. caviae primers were constructed by substituting five nucleotides in the above primer pair to obtain complete homology with the $C$. caviae VD4 sequence. CCVDF 5'-GTC CAG AGC TAC ATT TGA TGC-3' and CCVDR 5'-ATT TTG TTG ATT TGA AGC GAA GC-3'. C. caviae species confirmation was done by PCR high-resolution melting (HRM) curve analysis as described by Robertson et al., using DNA of the C. caviae reference strain (GPIC) as positive control [18].

Reactions for the VD4 PCR were performed in the Stratagene MX3005P QPCR system (incorporated in the Siemens Versant kPCR system). The uracil-N-glycosylase system (UNG) was used to prevent false-positive reactions due to amplicon carry over. After optimisation, the final reaction volume $(25 \mu \mathrm{l})$ included $5 \mu \mathrm{l}$ eluate, $12.5 \mu \mathrm{l}(2 \mathrm{x})$ Greenmaster qPCR mix with ROX reference dye, uracil-N-glycosylase (Jena biosciences, Jena, Germany) and $0.5 \mu \mathrm{M}$ of each primer. The realtime PCR steps were as follows: 1) $50^{\circ} \mathrm{C}$ for $\left.2 \mathrm{~min}, 2\right)$ $95^{\circ} \mathrm{C}$ for $\left.3 \mathrm{~min}, 3\right) 40 \mathrm{cycles}$ of $95^{\circ} \mathrm{C}$ for $5 \mathrm{sec}$, and $60^{\circ} \mathrm{C}$ for $60 \mathrm{sec}$. Fluorescence was detected in the FAM channel and normalised on the ROX signal. Subsequently, a dissociation curve was generated by continuous fluorescence acquisition from 60 to $95^{\circ} \mathrm{C}$ to observe possible additional PCR products and establish the formation of the expected PCR amplicon by determining the melting temperature (Tm). At first, all reference genotypes were used as positive controls in each run. For ease of application, we decided later to use only three genotypes (A, C and D) as controls.

\section{Validation of the VD4 PCR}

Analytical sensitivity was determined by testing 10 -fold dilutions of the commercially available Amplirun C. psittaci genomic DNA control starting from $10^{4}$ genome equivalents per $\mathrm{PCR}$ reaction. Serial dilutions were prepared in Tris/EDTA buffer, $\mathrm{pH}$ 8.0, supplemented with $20 \mathrm{ng} / \mu \mathrm{l}$ salmon sperm DNA). Reactions were performed in triplicate. Limiting dilutions were tested with and without previous nucleic acid extraction. When applying nucleic acid extraction, a matrix of C. psittaci DNA-negative, pooled and liquefied sputum samples was used. Sequence analysis was performed only on the lowest positive dilution series to confirm the identity of the positive control strain. For comparison, all dilutions were also tested with the previously described full-length ompA PCR and the diagnostic PCR [7,13].

Specificity was determined on a panel of bacterial and yeast species commonly encountered in human (respiratory) specimens (Table 1). Strains were diluted to a 0.5 McFarland standard turbidity equivalent to ca $10^{8}$ colony-forming units (CFU)/ml, and $250 \mu \mathrm{l}$ of this suspension was subsequently subjected to nucleic acids purification. Diagnostic specificity was tested using 20
TABLE 1

Strains used for specificity testing of the Chlamydia psittaci VD4 PCR $(\mathrm{n}=33)$

\begin{tabular}{|c|c|c|}
\hline Species & Strain $^{a}$ & VD4 PCR \\
\hline Klebsiella pneumoniae & ATCC 700603 & negative \\
\hline Klebsiella pneumoniae & ATCC 13883 & negative \\
\hline Streptococcus pyogenes & ATCC 19615 & negative \\
\hline Streptococcus pneumoniae & ATCC 6303 & negative \\
\hline Streptococcus agalactiae & SKML 1905 & negative \\
\hline Staphylococcus aureus & ATCC 25923 & negative \\
\hline Staphylococcus aureus & ATCC 29213 & negative \\
\hline Staphylococcus epidermidis & ATCC 12228 & negative \\
\hline $\begin{array}{l}\text { Staphylococcus aureus } \\
\text { (meticillin-resistant) }\end{array}$ & ATCC 43300 & negative \\
\hline Enterococcus faecalis & ATCC 29212 & negative \\
\hline Enterococcus faecium & ATCC 35667 & negative \\
\hline Moraxella catarrhalis & SKML 967 & negative \\
\hline Haemophilus parainfluenzae & ATCC 7901 & negative \\
\hline Haemophilus influenzae & ATCC 35056 & negative \\
\hline Neisseria meningitidis & ATCC 13090 & negative \\
\hline Legionella pneumophila & SKML 2013 & negative \\
\hline Bacillus cereus & ATCC 11778 & negative \\
\hline Enterobacter aerogenes & ATCC 35028 & negative \\
\hline Proteus vulgaris & ATCC 13315 & negative \\
\hline Proteus mirabilis & NCTC 10975 & negative \\
\hline Escherichia coli & ATCC 25922 & negative \\
\hline Pseudomonas aeruginosa & ATCC 27853 & negative \\
\hline Burkholderia cepacia & ATCC 25416 & negative \\
\hline Bacteroides fragilis & ATCC 25285 & negative \\
\hline Peptostreptococcus anaerobius & ATCC 27337 & negative \\
\hline Prevotella melaninogenica & ATCC 25845 & negative \\
\hline Bacteroides thetaiotaomicron & ATCC 29741 & negative \\
\hline Candida albicans & ATCC 90028 & negative \\
\hline Candida tropicalis & ATCC 13803 & negative \\
\hline Candida krusei & ATCC 6258 & negative \\
\hline Candida glabrata & ATCC 90030 & negative \\
\hline Mycoplasma pneumoniae & QCMD CPMP13-09 & negative \\
\hline Chlamydia pneumoniae & QCMD CPMP13-05 & negative \\
\hline
\end{tabular}

ATCC: American Type Culture Collection; NCTC: national collection of type cultures; QCMD: external quality assessment samples; SKML: Dutch quality control assessment strains.

human respiratory samples, previously tested negative for C. psittaci DNA by our previously described $C$. psittaci PCR [7]. Clinical sensitivity was determined on all C. psittaci PCR-positive clinical samples sent to our laboratory with a request for genotyping.

\section{Sequence analysis}

Sequence analysis was performed by an external Sanger sequencing facility (Baseclear BV, Leiden, the Netherlands). A 1:10 dilution of the amplification product in PCR-grade water was added to the forward or reverse primer with a final primer concentration 
Lower detection limit of the Chlamydia psittaci VD4 PCR and comparison with the diagnostic PCR and the previously described full-length ompA PCR

\begin{tabular}{|c|c|c|c|c|c|c|}
\hline \multirow{2}{*}{ Copies/PCR } & Diagnostic PCR & VD4 PCR & $\begin{array}{c}\text { Full-length ompA } \\
\text { PCR }\end{array}$ & Diagnostic PCR & VD4 PCR & $\begin{array}{c}\text { Full-length ompA } \\
\text { PCR }\end{array}$ \\
\hline & \multicolumn{3}{|c|}{ without nucleic acid extraction } & \multicolumn{3}{|c|}{ with nucleic acid extraction ${ }^{a}$} \\
\hline 10,000 & $3 / 3$ & $3 / 3$ & $3 / 3$ & Not done & Not done & Not done \\
\hline 1,000 & $3 / 3$ & $3 / 3$ & $3 / 3$ & $3 / 3$ & $3 / 3$ & $3 / 3$ \\
\hline 100 & $3 / 3$ & $3 / 3$ & $3 / 3^{b}$ & $3 / 3$ & $3 / 3$ & $3 / 3^{c}$ \\
\hline 10 & $3 / 3$ & $3 / 3$ & $0 / 3$ & $1 / 3$ & $2 / 3$ & $0 / 3$ \\
\hline 1 & $3 / 3$ & $2 / 3$ & $0 / 3$ & $0 / 3$ & $0 / 3$ & $0 / 3$ \\
\hline 0.1 & $0 / 3$ & $0 / 3$ & Not done & $0 / 3$ & $0 / 3$ & Not done \\
\hline Negative control & Negative & Negative & Negative & Negative & Negative & Negative \\
\hline
\end{tabular}

Results shown as number of positive samples vs number of samples tested.

a Nucleic acid extraction of the dilution series in a background of C. psittaci DNA-negative pooled and liquefied sputum.

b All three weak reactions.

One of three was a weak reaction.

of $1 \mathrm{pmol} / \mu \mathrm{l}$. Sequences were delivered by email as original peak plots. The forward and reverse overlapping sequences were edited to obtain the complete sequence. Alignment and calculation of a similarity index p-distance was done with MEGA 5.1 [19]. The newly discovered VD4 genotype was subjected to complete ompA sequencing as previously described [13]. A phylogenetic tree was constructed using the neighborjoining method. Reference ompA genotype sequences A-F, E/B and C. abortus (strain S26/3) available in the GenBank database (accession numbers AY762608-12 and AF269261) were included in this analysis.

Data acquisition and descriptive statistics Systematically collected data concerning notified human cases from September 2008 until the end of October 2013 were obtained anonymously from the national database for notifiable diseases at the Dutch Centre for Infectious Disease Control as far as possible. Age, sex, hospital admission, mortality, probable country of acquisition and suspected source of infection were noted. Occasionally, additional information was provided on submitted laboratory forms or provided via personal communication.

\section{Results}

\section{Validation of the VD4 PCR}

The newly designed primer set allowed for amplification of ompA VD4 regions of all nine C. psittaci reference strains. The lowest detection limit was 1 to 10 copies per PCR (Table 2). In a background of sputum, sensitivity was slightly lower, but still 10 to 100 copies per PCR. Dissociation curves showed only one PCR amplification product for each genotype. The genotypes were visible as dissociation peaks with Tm's ranging from 79 to $83^{\circ} \mathrm{C}$. Several replicates of the reference genotypes showed overlap between the $\mathrm{Tm}$ of the different genotypes. It was not possible to separate each genotype solely by Tm. The CPS13 panel was tested during validation and all truly positive samples were detected, and all negative samples were correctly identified as well. Specificity was $100 \%$ based on 33 commonly encountered bacterial and yeast species and 20 human respiratory samples. Sixty-nine $C$. psittaci real-time PCR-positive samples from 66 human individuals were available for typing. The expected amplification product was obtained in 66 of 69 vailable human samples. The $\mathrm{Ct}$ values (quantification cycle) of these clinical samples ranged from 22 to 38 cycles. Three of 69 samples were negative in the VD4PCR. Two of them contained C. caviae (see below), leaving only one of the remaining 67 samples untypable. Overall, the sensitivity of this method compared with our real-time diagnostic PCR was 98\% (66 genotypes from 67 typable samples).

In our hands, the method (excluding technician costs) costs ca EUR 22 per sample. This includes four PCR controls per run, nucleic acid extraction, PCR reagent and two sequence reactions. When needed, a typing result can be obtained within 24 hours.

\section{Sequence analysis and distribution of genotypes}

During validation, the Amplirun C. psittaci genomic DNA control (only on the lowest positive dilution series), all reference strains and the CPS13 panel were successfully sequenced. All 66 VD4 PCR-positive clinical samples were sequenced revealing $C$. psittaci genotype $A$ in 42 samples. Genotype B was found in 14 samples, $E / B$ was found in two samples and genotype $C$ in one sample.

Four samples revealed a new identical sequence type. Sequence analysis showed this strain to be a unique 


\section{FIGURE}

Phylogenetic tree displaying the Chlamydia psittaci ompA sequence HE687292 in relation to reference genotypes A-F and $\mathrm{E} / \mathrm{B}$

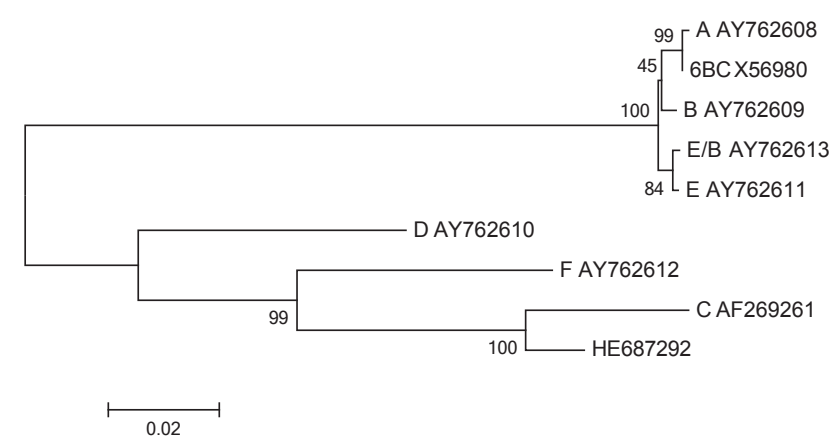

Neighbor-joining method, Jukes-Cantor model, using 1,000 bootstraps created with MEGA.

ompA genotype with homology to the ompA of both genotype $C$ and $D$. In the similarity calculation the sequence was most similar to reference genotype $C$ strain $(95 \%$ and $86 \%$ similarity to the ompA VD4 of genotype $C$ and $D$ respectively). These four samples were subjected to full-length $o m p A$ sequence analysis including all four variable domains. Full-length ompA could only be obtained for two of the four samples. These two full-length ompA sequences revealed an identical but new genotype in both samples. The sequence was submitted to the EMBL nucleotide sequence database and assigned reference number HE687292. The Figure shows the phylogentic relationships between the new genotype and genotypes $A-F$ and E/B. BLAST search did not reveal an identical sequence. Phylogenetic analysis showed the ompA gene of this strain to be most similar to that of the $C$. psittaci genotype C (96\% homologous to genotype C) but still discordant in 37 nucleotides resulting in nine different amino acids.

\section{Chlamydia caviae and Chlamydia abortus}

One sample contained C. abortus. Two VD4 PCRnegative samples from another patient were suspected to contain C. caviae DNA rather than C. psittaci DNA. This assumption was based on information from public health officials, who told us that the patient showed clinical symptoms after purchasing guinea pigs. C. caviae was indeed detected by use of $C$. caviae-specific primers and subsequent sequence analysis of the amplified ompA VD4 gene region. Both samples were also analysed by a PCR-HRM and confirmed positive for C. caviae.

Descriptive epidemiology

For 54 of the 66 PCR-positive patients, data were available in the national notification database.
TABLE 3

Characteristics of notified patients harbouring Chlamydia psittaci genotype A and B, the Netherlands, 2008 to 2013 $(\mathrm{n}=50)$

\begin{tabular}{|c|c|c|}
\hline Genotype & $A(n=37)$ & $B(n=13)$ \\
\hline Age in years: median (IQR) & $63(51-72)$ & $70(62-73)$ \\
\hline Sex (male) & 27 & 11 \\
\hline Deaths & 1 & 0 \\
\hline \multicolumn{3}{|c|}{ Probable source of infection (location) ${ }^{a}$} \\
\hline Home & 21 & 10 \\
\hline Bird show & 4 & 0 \\
\hline Bird dealer/bird dealing company & 3 & 0 \\
\hline Pet shop & 2 & 1 \\
\hline Public resort & 1 & 0 \\
\hline Abroad (farm) & 0 & 1 \\
\hline Unknown/not reported & 10 & 2 \\
\hline \multicolumn{3}{|c|}{ Probable source of infection (type of bird)a } \\
\hline Columbiformes & 0 & 10 \\
\hline Captive & 0 & 8 \\
\hline Wild & 0 & 3 \\
\hline Psittaciformes ${ }^{\mathrm{b}}$ & 8 & 0 \\
\hline Passeriformes ${ }^{c}$ & 5 & 0 \\
\hline Anseriformes (duck) & 0 & 1 \\
\hline Galliformes (pheasant) & 1 & 0 \\
\hline Unofficial bird groups & 0 & 0 \\
\hline Poultry & 3 & 2 \\
\hline Wild, free ranging birds & 3 & 0 \\
\hline Aviary birds & 6 & 0 \\
\hline Unknown/not reported & 15 & 1 \\
\hline \multicolumn{3}{|l|}{ Date of disease onset } \\
\hline First quarter & 17 & 3 \\
\hline Second quarter & 14 & 2 \\
\hline Third quarter & 4 & 6 \\
\hline Fourth quarter & 2 & 2 \\
\hline
\end{tabular}

More than one source could be noted.

b Four parakeets, one parrot, one cockatiel, one budgerigar, one unidentified parrot-like bird.

Two zebra finches, one canary, one jay, one siskin.

Characteristics associated with infection with either genotype A or B are presented in Table 3.

Among all 54 cases, men predominated, one death was reported and all were admitted to hospital. One person probably acquired the infection outside of the Netherlands. Exposure to Psittaciformes and Passeriformes was reported for patients harbouring genotype A, while exposure to Columbiformes predominated among patients harbouring genotype $B$. Remarkable is the large proportion of genotype $A$ cases in the first half of the year: 31 cases vs six in the second half (Table 3 ). 
C. abortus was found in one patient. This patient, suffering from severe pneumonia requiring admission to an intensive care unit, was living on a farm raising sheep and goats [20]. The C. caviae-positive patient was only diagnosed because an extensive diagnostic investigation took place for sepsis of unknown origin, revealing psittacosis as the most likely diagnosis. The patient had recently purchased two young guinea pigs before becoming ill [21]. The new unique ompA sequence was found in four cases. In none of the four could a direct link to specific birds be found, although one of the infected people was a volunteer working with and exposed to many different kinds of birds. One case with a genotype $C$ infection was detected. This case was related to a bird hospital.

\section{Discussion}

In this study, we present a simple, sensitive and cheap genotyping method to detect $C$. psittaci genotypes ( $A-F$, $\mathrm{E} / \mathrm{B}, \mathrm{WC}, \mathrm{M}_{56}$ ) and the closely related species $C$. abortus. The sensitivity of $98 \%$ compared with our real-time diagnostic PCR and a specificity of $100 \%$ were satisfactory. A result can be obtained in ca 24 hours. The lower detection limit of the VD4 PCR (at least 10 copies per reaction) is very sensitive and comparable to previously used C. psittaci ompA typing methods [9]. Geens et al. required separate $P C R$ reactions for each genotype while our method is a singleplex format [9]. Although the VD4 PCR was validated in only one laboratory, we were still able to detect the genotype in 66 of 67 typable samples sent from across the Netherlands.

Although the dissociation curve analyses could roughly separate the $C$. psittaci reference strains used in this study, this method was not accurate enough on its own. In particular, overlap occurred in the Tm for genotypes A, B, E and E/B. Mitchell et al., using dedicated equipment for high-resolution melting curve analysis, also found $21 \%$ of their tested positive samples to be untypable owing to inconclusive melting curve data [10].

To the best of our knowledge, the current study characterises the largest series of human-derived psittacosis strains described to date. In the past we had analysed a limited number of 10 human strains originating from psittacosis outbreaks and sporadic cases. As in the present study, genotype $A$ was the most prevalent strain [13]. Recently, an outbreak of psittacosis was described in Sweden. Twelve samples were available for ompA genotyping but sequencing of the ompA was successful in only four of them [14]. It should be noted that many $C$. psittaci typing methods described previously included hardly any human clinical samples [4,9-12]. They were validated mainly on bird samples or cultured strains. Validation on human samples is needed because the clinical matrix (for example sputum and bronchoalveolar lavage fluids) and the bacterial load can differ substantially between birds and humans.
Many of the genotype A-positive samples were obtained in spring 2011, during a period of increased psittacosis notifications. It seems that this temporary increase was in part due to these genotype A strains. A similar observation was described recently by Rehn et al. who reported a threefold increase in notified psittacosis cases from January to April 2013 [14]. A matched case-control study showed that cases were more likely than controls to have been cleaning bird feeders or were exposed to bird droppings in other ways.

Until now, a source for this temporary increase in the Netherlands of psittacosis notifications in Spring 2011 has not been found. This clearly emphasises the need for genotyping C. psittaci strains in human samples prospectively, as it could provide earlier information on probable avian sources, allowing for appropriate outbreak control measures. In the spring of 2013, the same effect was seen, albeit on a smaller scale. Within three months, eight people were infected with $C$. psittaci genotype $A$. Three of these eight were traced back to a bird show. Bird shows present a zoonotic risk. Visitors can be infected during their visit or afterwards as psittacine and passeriforme birds are often traded and disseminated at such events which are mainly held in the spring. In our dataset, genotype $A$ strains were more prominently found in the first half of the year. Genotype A is most often associated with Psittaciformes. This genotype is highly virulent for these birds, which excrete the bacterium in large amounts for long periods of time [5]. This might be one of the reasons of the high virulence in humans. The high proportion of genotype A could possibly be related to more intensive exposure to the main bird source of these genotypes (Psittaciformes). These birds are frequently kept as pets inside the house, while birds harbouring the other genotypes more often live outside a person's home. Remarkable is the exposure to Passeriformes in patients harbouring genotype A strains, possibly also due to exposure to these birds as pets. Analysis of the fluctuations in genotypes and possible causes should be a subject of ongoing surveillance. Genotype B is mainly associated with Columbiformes. In this sample set, we found 14 such strains. Previous research also determined genotype $B$ to be the second most prevalent genotype in humans [13].

Four patients were infected with a new C. psittaci ompA VD4 genotype, showing the highest ompA VD4 sequence homology with the genotype C GR9 strain. Full-length ompA could only be obtained for two of these four cases, underlining the lack of sensitivity of this typing method. The DNA and amino acid sequence of the full-length ompA/MOMP of this strain confirmed its unique sequence as we could not find a single match by BLAST. This raises the question of which birds or animals host these strains. Two of the samples were obtained in the context of a previously described outbreak in which a bird source could not be identified [15]. 
C. abortus was found in one patient. In the Netherlands, C. abortus is known to be endemic in sheep and goats [22]. Human C. abortus infections have been described. The infection can cause severe septic shock and fetal loss in pregnant women [23-25]. In most cases, testing for psittacosis is only performed when medical history reveals obvious bird contact. Therefore underestimation of these pulmonary $C$. abortus cases is quite likely. The same is true for the $C$. caviae-positive patient. It was only due to the sepsis of unknown origin that an extensive diagnostic investigation was done, revealing psittacosis as the most likely diagnosis based on a positive PCR of the conserved domain of ompA (which besides $C$. psittaci, also detects $C$. felis, $C$. caviae, and C. abortus). The discrepancy of this positive diagnostic PCR and the negative VD4 PCR led us to consider C. caviae as the cause of this infection, which was confirmed by molecular characterisation. Knowledge on the zoonotic potential of $C$. caviae is limited and until now, $C$. caviae has not been linked to fulminant sepsis in humans [26-28].

Human medicine should be aware of the zoonotic potential of Chlamydia as there is accumulating evidence that these species are more abundant in animals than previously assumed [6]. These cases also stress the need for close collaboration of physicians, medical microbiologists and public health officials involved in the notification process, as crucial information such as potential animal reservoirs with their associated Chlamydia can be missed. The distribution of genotypes in human hosts as found in this study should be carefully considered with respect to geographical location. The local fauna could be relevant when interpreting the results, and extrapolating them to other countries is probably premature. The interaction between human behaviour (urban vs rural) and the present wild bird species (tropical vs non-tropical) could influence local epidemiology. Accidental introduction of invasive, exotic pet bird species or invasion of foreign bird species could create a niche for certain genotypes, including genotypes not present in this study, and lead to unexpected increases in psittacosis cases [29].

In conclusion, this study shows that genotype $A$ and $B$ were the most prevalent causative strains of human psittacosis in the Netherlands. Psittacosis is a clinical syndrome caused by diverse $C$. psittaci genotypes, but typing results suggest that the clinical signs and symptoms are quite similar to closely related zoonotic $C$. abortus and $C$. caviae infections. The discovery of a unique ompA sequence points to currently unknown links between human cases and avian or other animal reservoirs.

\section{Accession number}

The EMBL accession number for the newly described Chlamydia psittaci genotype is HE687292.
Acknowledgements

The authors would like to acknowledge the following persons for their support: N. van Maarsenveen, molecular medical microbiologist at Rijnstate Medical Centre, provided additional data concerning the archived samples. K. Frijns, technician at the Medical Microbiology department Orbis Medical Centre, determined the ompA gene sequence (EMBL accession number HE687292). K. De Puysseleyr and A. Dumont at the Department of Molecular Biotechnology, Ghent University, performed the PCR-HRM for C. caviae and prepared genomic DNA of all C. psittaci reference strains and of $C$. caviae GPIC, respectively.

Financial support: The Dutch Ministery of Health, Welfare and Sport, National Institute for Public Health and the Environment, Bilthoven, the Netherlands, through the Public Health Diagnostic fund of the regional support for reinforcement of infectious disease control (grantnumber 3910014586) provided partial financial support of this study. Baseclear BV, Leiden, The Netherlands partially supported sequence analysis. This study was partially funded by the Belgian Federal Public Service of Health, Food Chain Safety and Environment (convention RF 6177).

Conflict of interest

None declared.

\section{Authors' contributions}

Heddema: idea and design of the study, wrote the manuscript. Bongaerts: performed and analysed most of the typing results, revised the article draft and approved the final manuscript. Van Hannen, Ten Hove and De Wever: submitted archived samples, collected data, revised the article draft and approved the final manuscript. Dijkstra: revealed and analysed demographic and epidemiologic data, revised the article draft and approved the final manuscript. Vanrompay: Cultured and provided all control strains, analysed crucial samples (C. caviae), co-designed the study, revised the article draft substantially and approved the final manuscript.

\section{References}

1. Everett KD, Bush RM, Andersen AA. Emended description of the order Chlamydiales, proposal of Parachlamydiaceae fam. nov. and Simkaniaceae fam. nov., each containing one monotypic genus, revised taxonomy of the family Chlamydiaceae, including a new genus and five new species, and standards for the identification of organisms. Int J Syst Bacteriol. 1999;49(Pt 2):415-40. http://dx.doi.org/10.1099/00207713-49-2-415 PMID:10319462

2. Stephens RS, Myers G, Eppinger M, Bavoil PM. Divergence without difference: phylogenetics and taxonomy of Chlamydia resolved. FEMS Immunol Med Microbiol. 2009;55(2):1159. http://dx.doi.org/10.1111/j.1574-695X.2008.00516.x PMID:19281563

3. Kuo CC, Stephens RS, Bavoil PM, Kaltenboeck B. Genus Chlamydia Jones, Rake and Stearns 1945, 55. In: Krieg NR, Staley JT, Brown DR, Hedlund BP, Paster BJ, Ward W, et al, editors. Bergey's manual of systematic bacteriology. 2nd ed; Vol 4. Heidelberg: Springer; 2011. p. 846-65.

4. Pannekoek Y, Dickx V, Beeckman DS, Jolley KA, Keijzers WC, Vretou E, et al. Multi locus sequence typing of Chlamydia reveals an association between Chlamydia psittaci genotypes and host species. PLoS ONE. 2010;5(12):e14179. http://dx.doi. org/10.1371/journal.pone.0014179 PMID:21152037

5. Harkinezhad T, Geens T, Vanrompay D. Chlamydophila psittaci infections in birds: a review with emphasis on zoonotic consequences. Vet Microbiol. 2009;135(1-2):68-77. http:// dx.doi.org/10.1016/j.vetmic.2008.09.046 PMID:19054633

6. Reinhold P, Sachse K, Kaltenboeck B. Chlamydiaceae in cattle: commensals, trigger organisms, or pathogens? 
Vet J. 2011;189(3):257-67. http://dx.doi.org/10.1016/j. tvjl.2010.09.003 PMID:20980178

7. Heddema ER, Beld MG, de Wever B, Langerak AA, Pannekoek Y, Duim B. Development of an internally controlled real-time PCR assay for detection of Chlamydophila psittaci in the LightCycler 2.0 system. Clin Microbiol Infect. 2006;12(6):571-5. http:// dx.doi.org/10.1111/j.1469-0691.2006.01417.x PMID:16700707

8. van der Bruggen T, Kaan JA, Heddema ER, van Hannen EJ, de Jongh BM. [Rapid diagnosis of psittacosis using a recently developed real-time PCR technique]. Ned Tijdschr Geneeskd. 2008;152(34):1886-8. PMID:18788681

9. Geens T, Dewitte A, Boon N, Vanrompay D. Development of a Chlamydophila psittaci species-specific and genotype-specific real-time PCR. Vet Res. 2005;36(5-6):787-97. http://dx.doi. org/10.1051/vetres:2005035 PMID:16120253

10. Mitchell SL, Wolff BJ, Thacker WL, Ciembor PG, Gregory CR, Everett KD, et al. Genotyping of Chlamydophila psittaci by realtime PCR and high-resolution melt analysis. J Clin Microbiol. 2009;47(1):175-81. http://dx.doi.org/10.1128/JCM.01851-08 PMID:19005152

11. Laroucau K, Thierry S, Vorimore F, Blanco K, Kaleta E, Hoop R, et al. High resolution typing of Chlamydophila psittaci by multilocus VNTR analysis (MLVA). Infect Genet Evol. 2008;8(2):171-81. http://dx.doi.org/10.1016/j. meegid.2007.12.002 PMID:18242149

12. Sachse K, Laroucau K, Vorimore F, Magnino S, Feige J, Müller W, et al. DNA microarray-based genotyping of Chlamydophila psittaci strains from culture and clinical samples. Vet Microbiol. 2009;135(1-2):22-30. http://dx.doi.org/10.1016/j. vetmic.2008.09.041 PMID:18950965

13. Heddema ER, van Hannen EJ, Duim B, Vandenbroucke-Grauls CM, Pannekoek Y. Genotyping of Chlamydophila psittaci in human samples. Emerg Infect Dis. 2006;12(12):1989-90. http:// dx.doi.org/10.3201/eid1212.051633 PMID:17326961

14. Rehn M, Ringberg H, Runehagen A, Herrmann B, Olsen $B$, Petersson AC, et al. Unusual increase of psittacosis in southern Sweden linked to wild bird exposure, January to April 2013. Euro Surveill. 2013;18(19):20478. PMID:23725809

15. McGuigan CC, McIntyre PG, Templeton K. Psittacosis outbreak in Tayside, Scotland, December 2011 to February 2012. Euro Surveill. 2012;17(22):20186. PMID:22687915

16. Untergasser A, Nijveen $H$, Rao X, Bisseling T, Geurts $R$ Leunissen JA. Primer3Plus, an enhanced web interface to Primer3. Nucleic Acids Res. 2007;35(Web Server issue):W71-4.

17. Bikandi J, San Millán R, Rementeria A, Garaizar J. In silico analysis of complete bacterial genomes: PCR, AFLP-PCR and endonuclease restriction. Bioinformatics. 2004;20(5):7989. http://dx.doi.org/10.1093/bioinformatics/btg491 PMID:14752001

18. Robertson T, Bibby S, O'Rourke D, Belfiore T, Lambie H, Noormohammadi AH. Characterization of Chlamydiaceae species using PCR and high resolution melt curve analysis of the 16S rRNA gene. J Appl Microbiol. 2009;107(6):201728. http://dx.doi.org/10.1111/j.1365-2672.2009.04388.x PMID:19583801

19. Tamura K, Peterson D, Peterson N, Stecher G, Nei M, Kumar S. MEGA5: molecular evolutionary genetics analysis using maximum likelihood, evolutionary distance, and maximum parsimony methods. Mol Biol Evol. 2011;28(10):2731-9. http:// dx.doi.org/10.1093/molbev/msr121 PMID:21546353

20. Rijksinstituut voor Volkgezondheid en Milieu. Gesignaleerd: Binnenlandse signalen Chlamydia abortus pneumonie [Signaled: Chlamydia abortus pneumonia]. Infectieziekten Bulletin. 2012;23(6):162. Dutch. Available from: http://www.rivm.nl/Documenten_en_publicaties/ Algemeen_Actueel/Uitgaven/Infectieziekten_Bulletin/ Jaargang_23_2012/Juli_2012/Inhoud_juli_2012/ Gesignaleerd_tot_en_met_14_juni_2012

21. Teirlinck AC, van Asten L, Brandsema PS, Dijkstra F, Donker GA, Euser SM, et al. Psittacose. In: Jaarrapportage surveillance respiratoire infectieziekten 2013. [Psittacosis. In: Annual report on surveillance of respiratory infectious diseases 2013]. Bilthoven: Rijksinstituut voor Volksgezondheid en Milieu; 2014. Dutch. Available from: http://www.rivm.nl/bibliotheek/ rapporten/150002006.pdf

22. van den Brom R, Lievaart-Peterson K, Luttikholt S, Peperkamp $\mathrm{K}$, Wouda W, Vellema P. Abortion in small ruminants in the Netherlands between 2006 and 2011. Tijdschr Diergeneeskd. 2012;137(7):450-7. PMID:22900421

23. Meijer A, Brandenburg A, de Vries J, Beentjes J, Roholl P, Dercksen $D$. Chlamydophila abortus infection in a pregnant woman associated with indirect contact with infected goats. Eur J Clin Microbiol Infect Dis. 2004;23(6):487-90. http:// dx.doi.org/10.1007/s10096-004-1139-Z PMID:15141338

24. Pospischil A, Thoma R, Hilbe M, Grest P, Zimmermann D, Gebbers JO. [Abortion in humans caused by Chlamydophila abortus (Chlamydia psittaci serovar 1)]. Schweiz Arch Tierheilkd. 2002;144(9):463-6. http://dx.doi. org/10.1024/0036-7281.144.9.463 PMID:12677684

25. Kampinga GA, Schröder FP, Visser IJ, Anderson JM, Buxton D, Möller AV. [Lambing ewes as a source of severe psittacosis in a pregnant woman]. Ned Tijdschr Geneeskd. 2000;144(52):25004. PMID:11155507

26. Lutz-Wohlgroth L, Becker A, Brugnera E, Huat ZL, Zimmermann $\mathrm{D}$, Grimm $\mathrm{F}$, et al. Chlamydiales in guinea-pigs and their zoonotic potential. J Vet Med A Physiol Pathol Clin Med. 2006;53(4):185-93. http://dx.doi.org/10.1111/j.14390442.2006.00819.x PMID:16629952

27. Rohde G, Straube E, Essig A, Reinhold P, Sachse K. Chlamydial zoonoses. Dtsch Arztebl Int. 2010;107(10):174-80. PMID:20358033

28. Rodolakis A, Yousef Mohamad K. Zoonotic potential of Chlamydophila. Vet Microbiol. 2010;140(3-4):382-91. http:// dx.doi.org/10.1016/j.vetmic.2009.03.014 PMID:19345022

29. Dickx V, Kalmar ID, Tavernier P, Vanrompay D. Prevalence and genotype distribution of Chlamydia psittaci in feral Canada geese (Branta canadensis) in Belgium. Vector Borne Zoonotic Dis. 2013;13(6):382-4. http://dx.doi.org/10.1089/vbz.2012.1131 PMID:23654298 